\title{
Derechos humanos
}

de las niñas y los niños

y la prohibición del

matrimonio infantil

en los tratados

internacionales*/

Human Rights

of Children and

Prohibition of

Child Marriage in

International Treaties

* Recibido: 8 de julio de 2014. Aceptado: 14 de septiembre de 2014.

Tla-Melaua, revista de Ciencias Sociales. Facultad de Derecho y Giencias Sociales. Benemérita Universidad Autónoma de Puebla, México / issn: 1870-6916 / Nueva Época, Año 9, No 38, abril / septiembre 2015, pp. 140-160. 
En México, las niñas desde los 14 años y los niños desde los 16 pueden contraer matrimonio con el consentimiento de sus tutores. $\mathrm{Al}$ emanciparse, adquieren legalmente las obligaciones de una persona adulta y pierden los derechos humanos de los niños, lo cual, a esa edad, agudiza su estado de vulnerabilidad. Para evitar este problema, los tratados internacionales más progresistas en la materia han recomendado a los Estados parte legislar para prohibir el matrimonio infantil, estableciendo la edad mínima de 18 años para contraer matrimonio. El objetivo de este artículo es analizar, con base en los principios constitucionales del interés superior del menor, en relación con los principios de progresividad, interpretación conforme y pro persona, la obligación del Estado de cumplir con los tratados que garantizan una protección más eficaz a los derechos humanos de los niños.

\section{PALABRAS CLAVE}

Derechos humanos de los niños, matrimonio infantil, tratados internacionales, principios de interpretación.
In Mexico, girls from the age of 14 years old and boys from the age of 16 years old can get married with the authorization of their legal guardian. When they become emancipated, they acquire the obligations of an adult person and they lose their human rights as children, which at that age heightens their vulnerable state. To avoid this problem, the most progressive international treaties on the subject have recommended to Member States to legislate to prohibit child marriage establishing 18 as the minimum age for marriage. The objective of this article is to analyze, on the basis of constitutional principles representing the minor's best interests, in relation to the principles of progressiveness, with an interpretation in accordance with pro person principles and the State's obligation to comply with those treaties to ensure a more effective protection of the human rights of children.

\section{KEYWORDS}

Children human rights, child marriage, international treaties, interpretation principles.

\footnotetext{
* Profesor investigador en la Universidad Autónoma del Estado de México. (jjnaresh@uaemex.mx) ** Coordinador de la Maestría en Procesos Jurídicos del Centro Universitario Universidad Autónoma del Estado de México Texcoco. (richard_lic1@yahoo.com.mx)

*** Profesor en la Universidad Autónoma del Estado de México. (rodgarcia_135@hotmail.com)
} 
1. Emancipación de los menores de edad en razón del matrimonio / 2. Derechos humanos de los niños en la Constitución Federal y en los tratados internacionales / 3. El matrimonio infantil: restricción y supresión de derechos humanos de los niños / 4. Adecuación de la prohibición del matrimonio infantil en la legislación civil mexicana / 5. Conclusiones

\section{EMANCIPACIÓN DE LOS MENORES DE EDAD EN RAZÓN DEL MATR IMON I 0}

En la legislación civil mexicana, la mayoría de edad se obtiene al cumplir dieciocho años. A partir de ese momento, salvo las limitaciones que establezca la ley, las personas pueden disponer libremente de su persona y de sus bienes. Obtienen también la capacidad civil para contraer matrimonio, pues se presupone en las personas madurez para llevar una vida en común. ${ }^{1}$ Como fines del matrimonio se pueden señalar la comunidad de vida, el respeto, la igualdad y ayuda mutua, así como la libertad de procrear. ${ }^{2}$

La legislación civil federal, ${ }^{3}$ la del Distrito Federal y la de las entidades federativas establecen que los menores de edad también pueden contraer matrimonio, siempre y cuando cumplan ciertos requisitos. A este matrimonio, en el ámbito internacional, se le denomina como matrimonio infantil, definido como la unión de dos personas en la cual al menos una de ellas es menor de 18 años. ${ }^{4}$ Los menores de edad, para contraer matrimonio, generalmente requieren del consentimiento de quienes ejercen sobre ellos la patria potestad, o en su caso de dispensa judicial.

La edad mínima de los menores para contraer matrimonio es excepcionalmente de 14 años en la mujer y de 16 en el hombre, como se establece en la legislación civil federal y en algunas otras legislaciones como las de Aguas Calientes ${ }^{5}$ y Baja California. ${ }^{6}$ En cambio, en legislaciones civiles de estados

\footnotetext{
${ }^{1}$ Brena Sesma, Ingrid, "Reformas al código civil en materia de matrimonio", Revista de Derecho Privado, pp. 3-12, Nueva Época, Año 1, enero-abril de 2002, México, Instituto de Investigaciones Jurídicas de la UNAM, p. 3.

${ }^{2}$ Código Civil del Distrito Federal, art. 146. Última reforma publicada en la Gaceta Oficial el 28 de julio, 2014.

${ }^{3}$ Código Civil Federal. Última reforma publicada Dof 24 de diciembre, 2013.

${ }^{4}$ Asamblea Parlamentaria del Consejo de Europa sobre Matrimonios Forzados y Matrimonios de Niños. Resolución 1468, 5 de octubre, 2005, párr. 7.

${ }^{5}$ Código Civil del Estado de Aguas Calientes. Última reforma publicada en el Periódico Oficial 23 de agosto, 2013.

${ }^{6}$ Código Civil del Estado de Baja California. Última reforma publicada Periódico Oficial 19 de septiembre, 2014.
} 
como Campeche ${ }^{7}$ la edad es por igual de dieciséis años en la mujer y en el hombre; en la del Distrito Federal, como excepción, de dieciséis años para ambos contrayentes.

El matrimonio en los menores produce su emancipación y da por terminada la patria potestad, lo que equivale, con algunas excepciones, a la mayoría de edad. Como consecuencia, estos menores dejan de estar protegidos por los derechos humanos que tutelan a las niñas y los niños, y adquieren las obligaciones de una persona mayor. En la mayoría de los casos, estos menores emancipados no tienen la capacidad para cumplir con los fines del matrimonio, ni con los derechos y obligaciones de los adultos, lo cual incrementa su estado de vulnerabilidad.

Debido a esta situación, en el ámbito jurídico nacional e internacional se debate si los menores de edad deben tener o no el derecho de contraer matrimonio. En este debate es ineludible hacer referencia a los progresos que han alcanzado los derechos humanos en el mundo.

\section{DeRechos humanos de los niños en la CONSTItUCión FEDERAL Y EN LOS TRATADOS INTERNACIONALES}

En el sistema constitucional mexicano, el diez de junio de 2011 se reformó el artículo 1 de la Constitución Política de los Estados Unidos Mexicanos, ${ }^{8}$ dando origen a un nuevo paradigma de derechos humanos. El primer párrafo del citado artículo establece que todas las personas gozarán de los derechos humanos y de las garantías para su protección, reconocidas en la propia Constitución y en los tratados internacionales de los cuales el Estado mexicano sea parte.

Los derechos humanos son definidos como derechos públicos subjeti$\operatorname{vos}^{9}$ de carácter individual, social o político, que reconoce la Constitución y los tratados para cualquier persona por el simple hecho de ser humano, sin distinción alguna. ${ }^{10}$ Reúnen ciertos requisitos esenciales: derivar de la naturaleza humana, o tener relación directa con la dignidad humana, y ser universales y absolutos. ${ }^{11}$ Se les califica como derechos fundamentales

\footnotetext{
${ }^{7}$ Código Civil del Estado de Campeche. Última reforma publicada en el Periódico Oficial 15 de diciembre, 2011.

${ }^{8}$ Constitución Política de los Estados Unidos Mexicanos. Última reforma publicada Dof 07 de julio, 2014.

${ }^{9}$ Medellín Urquiaga, Ximena. Metodología para la enseñanza de la reforma constitucional en Materia de Derechos Humanos. Módulo 1. Principio pro persona, México, Suprema Corte de Justicia de la Nación (scjs), Oficina en México del Alto Comisionado de las Naciones Unidas para los Derechos Humanos (OAGnudH) y Comisión de Derechos Humanos del Distrito Federal (CDHDF), 2013, p. 71.

${ }^{10}$ Castilla Juárez, Karlos. "Un nuevo panorama constitucional para el derecho internacional de los derechos humanos en México", Estudios Constitucionales, pp. 123-164, año 9, núm. 2, Chile, Centro de Estudios Constitucionales de Chile Universidad de Talca, 2011, p. 140.

${ }^{11}$ Baltazar Robles, Germán Eduardo, El nuevo juicio de amparo. Las reformas constitucionales de junio de 2011, México, Germán Eduardo Baltazar Robles “Complejo Educativo de Desarrollo Integral”, México, 2011, p. 71.
} 
porque son instrumentos de protección de los bienes básicos de las personas reconocidos por la Constitución Federal.

Los derechos humanos son derechos sustantivos o de contenido material, de los cuales no pueden disponer ni los individuos ni los poderes públicos, ${ }^{12}$ en tanto las garantías para su protección son generalmente de tipo procesal o adjetivo, en razón de que su finalidad es devolver a su estado original los derechos humanos cuando hayan sido violados o afectados. ${ }^{13}$

Esta reforma dio inicio a un proceso que en el ámbito jurídico es conocido como "constitucionalización del derecho", ${ }^{14}$ lo cual significa, desde la teoría del neoconstitucionalismo, que en un Estado constitucional y democrático de derecho no es el legislador quien determina la ley, sino la Constitución. ${ }^{15}$ Esta teoría sostiene que las constituciones modernas se caracterizan porque las normas de derechos humanos que reconocen se encuentran redactas en forma de principios, esto es, carecen de una determinación exacta y absoluta, pues más bien dependen de la interpretación de sus posibilidades jurídicas. ${ }^{16}$

El párrafo primero del citado artículo 1 constitucional otorga a los tratados internacionales el carácter de fuente normativa de derechos humanos, con fuerza vinculatoria para el Estado. Las normas de derechos humanos de la Constitución se extienden e incorporan materialmente con las normas de derechos humanos establecidas en los tratados internacionales reconocidas por el Estado, ${ }^{17}$ formando lo que se conoce como bloque de constitucionalidad. ${ }^{18}$ Este bloque determina la validez de todas las normas del sistema jurídico mexicano y condiciona la de la legislación y la jurisprudencia.

Por "tratado" se entiende, de acuerdo al artículo 1 de la Convención de Viena sobre el Derecho de los Tratados, ${ }^{19}$ un acuerdo internacional celebrado por escrito entre Estados y regido por el derecho internacional, ya conste en un instrumento único o en dos o más instrumentos conexos cualquiera que sea su denominación particular. Los tratados internacionales sobre derechos humanos no son de naturaleza sinalagmática, es decir, no establecen bilateralmente derechos y obligaciones entre los Estados parte, sino obligaciones

\footnotetext{
${ }^{12}$ Castellanos Madrazo, José, El control de constitucionalidad de la ley en México, México, Porrúa, 2014, p. 426.

${ }^{13}$ Carbonell, Miguel, Los derechos humanos en México, México, Editorial Flores-unam, 2015, p. 4.

${ }^{14}$ Ortega García, Ramón, "La constitucionalización del derecho en México", Boletín Mexicano de Derecho Comparado, pp. 601-646, vol. 46, núm. 137, mayo-agosto, México, Universidad Nacional Autónoma de México-Instituto de Investigaciones Jurídicas, 2013, p. 603.

${ }^{15}$ Núñez Leiva, José Ignacio, Neoconstitucionalismo y control de constitucionalidad de la ley, México, Porrúa, 2013, p. 84.

${ }^{16}$ Carbonell, Miguel, 2015, op. cit., p. 91.

${ }^{17}$ Rodríguez Manzo, Graciela et al., Metodología para la enseñanza de la reforma constitucional en Materia de Derechos Humanos, México, Comisión de Derechos Humanos del Distrito Federal, 2013, p. 9.

${ }^{18}$ Sánchez Cordero, Olga M., "La tutela multinivel de los derechos fundamentales ante el nuevo paradigma constitucional”, en García Villegas Sánchez Cordero, Paula M., El control de convencionalidady las cortes nacionales, México, Porrúa, 2013, p. 5.

${ }^{19}$ Convención de Viena sobre el Derecho de los Tratados. Dof 14 de febrero, 1975.
} 
de los Estados ante los demás no para beneficio propio, sino para proteger los derechos humanos de las personas que habitan sus territorios, frente al propio Estado o a cualquier otro. ${ }^{20}$ Los tratados internacionales de derechos humanos, reúnen un conjunto de notas distintivas: constituirse como tratados normativos; contar con mecanismos de supervisión para la garantía a los derechos; y un particular alcance interpretativo, en función de su contenido normativo. $^{21}$

Se usan diversos vocablos para referirse a los tratados internacionales que tienen fuerza vinculatoria para los Estados parte, como pactos, convenios, acuerdos, recomendaciones, cartas constitutivas de diversos organismos especializados de la ONU, entre otros más. Estos instrumentos internacionales, para ampliar el significado de sus normas o precisar sus obligaciones, pueden emitir observaciones generales o comentarios, que igualmente tienen fuerza obligatoria. También existen las declaraciones de derechos, que únicamente pueden ser criterios orientadores dirigidos a los organismos responsables de formular o aplicar el derecho positivo interno o internacional; pero también pueden llegar a ser de carácter vinculatorio, en cuyo caso serán un tratado aun cuando incorrectamente se les llame "declaraciones".22

Los tratados internacionales sobre derechos humanos disfrutan de una especial naturaleza jurídica que los distingue de otro tipo de tratados, pues se espera que el Estado firmante emprenda un conjunto de medidas legislativas y de política pública para hacerlos efectivos. De acuerdo con el principio Pacta sunt servanda, establecido por el artículo 26 de la Convención de Viena sobre el Derecho de los Tratados, todo tratado obliga a las partes y debe ser cumplido de buena fe, sin que una parte pueda invocar las disposiciones de su derecho interno como justificación del incumplimiento de un tratado.

Los tratados internacionales de derechos humanos pueden ser de carácter general, dirigidos a la protección de todas las personas, o de carácter especial para proteger a determinados tipos de personas. ${ }^{23}$ Las niñas y los niños por su falta de madurez física y mental, en el ámbito jurídico internacional, son reconocidos como las personas más vulnerables en relación con la violación de los derechos humanos, razón por la cual necesitan de protección especial para hacer efectivos estos derechos. ${ }^{24}$

\footnotetext{
${ }^{20}$ Corcuera Cabezut, Santiago, Derecho constitucional y derecho internacional de los derechos humanos, México, Oxford, 2012, pp. 55 y 72.

${ }^{21}$ Caballero Ochoa, José Luis, La interpretación conforme, México, Porrúa, 2014, p. 30.

${ }^{22}$ Patiño Camarena, Javier, De los Derechos del Hombre a los derechos humanos, México, Editorial FloresInstituto de Investigaciones Jurídicas UnAm, 2014, p. 1137.

${ }^{23}$ Carbonell, Miguel, "Las obligaciones del Estado en el artículo $1^{\circ}$ de la Constitución Mexicana", pp. 63-102, en Carbonell, Miguel y Salazar, Pedro (coord.), La reforma constitucional de derechos humanos, México, Porrúa, 2014, p. 71.

${ }^{24}$ Declaración Universal de Derechos Humanos, artículo 25.2. Adoptada por México el 10 de diciembre, 1948 .
} 
Los derechos humanos de los niños tienen en México rango constitucional, como lo establece el párrafo noveno del artículo 4 de la CPEUM, que dice que en las decisiones y actuaciones del Estado se velará y cumplirá con el principio del interés superior de la niñez, garantizando de manera plena sus derechos. Uno de los objetivos primordiales del citado artículo es reconocer como derechos constitucionales todos los derechos de los niños establecidos en los diversos tratados internacionales que México ha suscrito. ${ }^{25}$ Para cumplir con este objetivo, el Estado expidió la Ley General para la Protección de Niñas, Niños y Adolescentes (en adelante LGDNNA), ${ }^{26}$ concebida para ser un mecanismo eficaz para la garantía y exigibilidad de los derechos humanos de todos los niños. ${ }^{27}$

El marco jurídico internacional que vincula al Estado mexicano para la protección integral de los niños se compone de instrumentos mundiales y regionales. En cuanto a los primeros, el instrumento fundamental es la Convención sobre los Derechos del Niño de 1989 (en adelante CDN) ${ }^{28}$ el cual debe interpretarse y aplicarse según el artículo 13 de la LGDNNA, en el marco de la Declaración Universal de Derechos Humanos, en el Pacto Internacional de Derechos Civiles y Políticos, ${ }^{29}$ en el Pacto Internacional de Derechos Económicos, Sociales y Culturales ${ }^{30}$ y en los convenios constitutivos de los organismos especializados y de las organizaciones internacionales que se interesan en el bienestar del niño.

Los primeros instrumentos internacionales en reconocer los derechos del niño fueron la Declaración Universal de los Derechos Humanos para los Niños ${ }^{31}$ y la Declaración de los Derechos del Niño. ${ }^{32}$ Como sus nombres indican, son una declaración de principios de carácter proteccionista, que contiene obligaciones para las personas o las instituciones, aunque no son textos jurídicamente vinculantes. ${ }^{33}$ Posteriormente, la Declaración Universal de Derechos Humanos y el Pacto Internacional de Derechos Civiles y Políticos reconocieron con carácter vinculatorio para los Estados parte el derecho de las niñas y los niños a ser protegidos por la familia, la sociedad y el Estado, libres de violencia, abuso y explotación.

\footnotetext{
${ }^{25}$ Tesis la. GXVI/2011, publicada en el Semanario Judicial de la Federación y su Gaceta, Novena Época, Tomo 34, septiembre de 2011, página 1034, de rubro "Derecho a la identidad de los niños".

${ }^{26}$ Ley General para la Protección de Niñas, Niños y Adolescentes. DoF 04 de diciembre, 2014.

${ }^{27}$ Moctezuma Lule, María C., De Jesús Viejo Plancarte, et al., Exposición de motivos de la Ley para la Protección de los Derechos de las Niñas, Niños y Adolescentes del Estado de México, México, LV Legislatura del Estado de México, 2004.

${ }^{28}$ Convención sobre los Derechos del Niño. DOF 25 de enero, 1991.

${ }^{29}$ Pacto Internacional de Derechos Giviles y Políticos, artículos 23 y 24. Dof mayo, 1981.

${ }^{30}$ Pacto Internacional de Derechos Económicos, Sociales y Culturales, artículo 10. Dof mayo, 1981.

${ }^{31}$ Declaración Universal de los Derechos Humanos para los Niños. Declaración de Ginebra de 1924.

${ }^{32}$ Declaración de los Derechos del Niño. Adoptada por México el 20 de noviembre, 1959.

${ }^{33}$ González Contró, Mónica, "La reforma constitucional pendiente en materia de derechos de niños, niñas y adolescentes. Cuestiones Constitucionales", Revista Mexicana de Derecho Constitucional, núm. 27, julio-diciembre, 2007.
} 
La Asamblea General de las Naciones Unidas, el 20 de noviembre de 1989, aprobó la CDN para asumir la obligación de ofrecer a los niños protección integral, la cual comprende la protección social y la protección jurídica. Al respecto, en su artículo 2.1 establece que los Estados parte tienen la obligación de garantizar a todos los seres humanos de menos de 18 años el disfrute de todos los derechos enunciados en la Convención. Para el efecto, dice en su artículo 4 que los Estados parte deberán adoptar todas las medidas legislativas para crear las normas internas y de otra índole para dar efectividad a los derechos reconocidos en la Convención. Por tanto, es un instrumento jurídicamente vinculante, que obliga a los Estados parte a crear normas internas para hacer efectivos los derechos y libertades de los niños reconocidos en la CDN, y cuyo incumplimiento puede acarrear responsabilidades y sanciones internacionales.

Actualmente, existe consenso entre los países para reconocer que es el instrumento más avanzado en esta materia, por lo cual ha sido ratificado por la mayoría de los Estados miembro de la Organización de las Naciones Unidas. Constituye la base fundamental para reconocer, a nivel internacional e interno de los países que la han adoptado (como sucede con México), la titularidad de derechos de niños, niñas y adolescentes. También se creó el Comité de los Derechos del Niño, un órgano de vigilancia que supervisa los progresos alcanzados por los Estados parte en el cumplimiento de la CDN, así como en el cumplimiento de las observaciones generales, las bases jurisprudenciales, y sus dos protocolos facultativos, uno en relación con los niños en conflictos armados y el otro sobre los niños víctimas de prostitución, tráfico y pornografia. ${ }^{34}$

La CDN representa una nueva concepción acerca de los niños. La normatividad internacional anterior sobre derechos del niño concebía a los menores desde una perspectiva asistencialista y como objeto de tutela y protección segregativa. Se limitaba a proteger la persona del menor. Sólo hacia el final del siglo xx los instrumentos internacionales reconocieron la subjetividad jurídica y política del niño en términos de ciudadanía y de plenos derechos, ${ }^{35}$ de tal modo que ahora se trata de garantizar los derechos humanos de todos los niños.

La CDN otorga una protección integral a los derechos humanos de los niños, señalando que estos tienen todos los derechos de los adultos, y adicionalmente derechos civiles, sociales y culturales específicos porque se encuentran en una

\footnotetext{
${ }^{34}$ Liwsky, Norberto Ignacio, "Hacia un sistema integral de justicia y políticas públicas acordes con el marco jurídico internacional", en Juan Carlos Gutiérrez Contreras, Memorias del seminario internacional los derechos humanos de los niños, niñas y adolescentes, pp. 28-50, México, Secretaría de Relaciones Exteriores, 2006, p. 30.

${ }^{35}$ Beloff, Mary, "Protección integral de derechos del niño vs. Derechos en situación irregular", en Juan Carlos Gutiérrez Contreras, op. cit., p. 86.
} 
etapa evolutiva que requiere de protección especial. ${ }^{36}$ Establece en su normatividad los siguientes principios fundamentales: no discriminación (artículo 2); el interés superior del niño (artículo 3); derecho a la vida, a la supervivencia y al desarrollo (artículo 6); el derecho de ser escuchado y tomado en cuenta (artículo 12).

En especial, el interés superior del niño es un principio fundamental que se debe observar en todas las medidas legislativas que correspondan a los niños. Estrechamente relacionado con lo anterior, se encuentra el principio de prioridad absoluta, lo cual significa que las autoridades le darán primacía absoluta a los derechos del niño antes que a cualquier otra cosa. Un principio más es la participación del Estado, la familia, la comunidad y del propio niño, como encargados de crear los mecanismos de exigibilidad que garanticen el efectivo cumplimiento de los derechos en cita. El último principio se refiere al papel fundamental que desempeña la familia en la garantía de los derechos del niño.

El niño debe crecer en el seno de la familia por ser el medio que mejor garantiza su desarrollo y protección; los padres son los responsables de cuidarlos y educarlos. Con esta finalidad, el Estado no sólo debe ayudar a la familia para el cumplimiento de sus responsabilidades, además tiene la obligación de evitar cualquier medida que separe al niño de la misma. Otros derechos de igual importancia que los anteriores son el derecho de autonomía progresiva, el de supervivencia, y el derecho al desarrollo integral. La CDN reconoce estos derechos como exigibles, y al niño como sujeto pleno de derechos para demandar, actuar y proponer.

Los derechos del niño son resumidos por O’Donnell ${ }^{37}$ bajo la doctrina de la protección integral, que comprende los siguientes aspectos: el niño como sujeto de derechos; el derecho a la protección especial; el derecho a condiciones de vida que permitan su desarrollo integral; el principio de la unidad de la familia, en corresponsabilidad con el Estado y la comunidad.

En el contexto interamericano no existe algún tratado dirigido específicamente a la protección de los derechos humanos de los niños, ${ }^{38}$ por lo cual los Estados de la región reconocen la complementariedad de las normas de la CDN en otros instrumentos de derechos humanos que se interesan en el bienestar del niño. Destaca en particular la Convención Americana sobre

\footnotetext{
${ }^{36}$ Pérez Contreras, María M., La protección de los derechos de la infancia. Un comentario legislativo a la Convención Sobre Derechos del Niño y el marco jurídico de protección nacional. Publicación electrónica, pp. 13-22, núm. 5, Instituto de Investigaciones Jurídica UNAM, 2011, p. 15.

${ }^{37}$ O’Donnell, Daniel, "La doctrina de la protección integral y las normas jurídicas vigentes en relación con la familia", en Juan Carlos Gutiérrez Contreras, op. cit., p. 120.

${ }^{38}$ González Contró, Mónica, "Derechos de niñas, niños y adolescentes", en Ferrer Mc-Gregor Poisot, Caballero Ochoa, José Luis, Steiner, Christian (coords.), Derechos Humanos en la Constitución: Comentarios de jurisprudencia constitucional e interamericana, pp. 639- 666, México, Suprema Corte de Justicia de la Nación, Universidad Nacional Autónoma de México, Fundación Konrad Adenauer, 2013, p. 646.
} 
Derechos Humanos, ${ }^{39}$ que integra una Relatoría Especial de la Niñez; la Comisión Interamericana de Derechos Humanos, como órgano de vigilancia; la Corte Interamericana de Derechos Humanos, como órgano jurisdiccional; ${ }^{40}$ así como el Protocolo Adicional a la Convención Americana de Derechos Humanos en Materia de Derechos Económicos, Sociales y Culturales (Protocolo de San Salvador). ${ }^{41}$ Otros instrumentos regionales de semejante importancia son la Convención sobre la Eliminación de todas las Formas de Discriminación contra la Mujer, ${ }^{42}$ y el Comité para la Eliminación de la Discriminación contra la Mujer.

La Convención Americana sobre Derechos Humanos representa en la materia el tratado fundamental para los Estados parte de la región. El artículo 19 establece que los niños tienen derecho a las medidas de protección por parte de su familia, de la sociedad y del Estado. La Corte Interamericana de Derechos Humanos ha expuesto que los niños, debido a su condición de vulnerabilidad, requieren de derechos especiales para su protección. Estos derechos deben permitirles ser considerados y tratados como seres humanos plenos, para desarrollarse en un ambiente que les garantice la satisfacción de las necesidades elementales para alcanzar un nivel de vida físico, espiritual, moral y social que los dignifique. ${ }^{43}$

\section{EL MATRIMONIO INFANTIL: RESTRICCIÓN Y SUPRESIÓN DE DERECHOS HUMANOS DE LOS NIÑOS}

La CDN define el concepto de niño diciendo: "Artículo 1. Para los efectos de la presenta Convención, se entiende por niño todo ser humano menor de dieciocho años de edad, salvo que, en virtud de la ley que le sea aplicable, haya alcanzado antes la mayoría de edad". La Convención basa en la edad de dieciocho años el criterio para establecer la diferencia entre niños y mayores de edad, lo cual resulta relevante para preservar la calidad de niño como sujeto titular de derechos especiales. ${ }^{44}$

\footnotetext{
${ }^{39}$ Convención Americana sobre Derechos Humanos. Pacto de San José de Costa Rica. Dof: septiembre, 2001.

${ }^{40}$ Corte Interamericana de Derechos Humanos. Dof 8 de diciembre, 1998.

${ }^{41}$ Protocolo Adicional a la Convención Americana de Derechos Humanos en Materia de Derechos Económicos, Sociales y Culturales. Dof: 01 de septiembre, 1998.

${ }^{42}$ Convención sobre la Eliminación de todas las Formas de Discriminación contra la Mujer. DOF: 12 de mayo, 1981.

${ }^{43}$ Tesis: 1a. CXV/2012 (10 $)$, publicada en el Semanario Judicial de la Federación y su Gaceta, Décima Época, Libro 9, Tomo 1, junio de 2012, p. 268, de rubro "Suplencia de la queja deficiente en favor de menores. El tribunal colegiado de circuito debe estudiar la constitucionalidad de una ley cuando se advierte que puede ser contraria al interés superior de aquéllos"; Tesis: I.5o.G. J/18, publicada en el Semanario Judicial de la Federación y su Gaceta, Novena Época, Tomo 33, junio de 2011, p. 1016, de rubro "Menores de edad. Aspectos a considerar para determinar sus derechos".

${ }^{44}$ García Ramírez, Sergio, Derechos Humanos de los menores de edad. Perspectiva de la jurisdicción interamericana, México, Universidad Nacional Autónoma de México-Instituto de Investigaciones Jurídicas, 2010, p. 23.
} 
La CDN dispone que sus normas sean aplicables a todos los menores de dieciocho años de edad, salvo que por alguna causa legal hayan alcanzado antes la mayoría de edad. La Convención reserva a los Estados arte la facultad para determinar una edad diversa para alcanzar antes la mayoría de edad. En el caso de México, de acuerdo con el sistema de facultades expresas establecido por la Constitución Federal para el Congreso de la Unión y las reservadas para las legislaturas estatales,${ }^{45}$ el legislador de cada entidad federativa puede determinar una edad diversa para alcanzar antes la mayoría de edad. Otra causa es la emancipación de los menores de dieciocho años en razón del matrimonio. En tal caso, la identificación de la persona como niño no prevalece, por lo cual pierde los derechos de los niños.

Los tratados internacionales señalan que, para salvaguardar los derechos del niño, la legislación de cada país debe prever una edad mínima para contraer matrimonio. La CDN no indica expresamente alguna edad, en tanto que otros tratados otorgan a los Estados parte una doble facultad: poder fijar la edad mínima para contraer matrimonio, y la facultad de dispensar el requisito de la edad establecida en su legislación interna, como lo establecen la Convención Americana sobre Derechos Humanos, en su artículo 17.2, y el Pacto Internacional de Derechos Civiles y Políticos en su artículo 23.2. La Convención sobre el Consentimiento para el Matrimonio, la Edad Mínima para Contraer Matrimonio y el Registro de los Matrimonios, ${ }^{46}$ dice en el artículo 2 que los Estados parte adoptarán las medidas legislativas convenientes para determinar la edad mínima para contraer matrimonio. Señala que no podrán contraer matrimonio quienes no hayan cumplido esa edad, salvo que la autoridad competente, por causas justificadas y en interés de los contrayentes, dispense el requisito de la edad.

La edad núbil es un criterio internacional sobre la edad mínima para contraer matrimonio, como lo señala la Declaración Universal de Derechos Humanos en su artículo 16, que dice que a esa edad las personas sin distinción alguna tienen derecho a casarse y fundar una familia. La edad núbil significa que a esa edad se alcanza la madurez sexual y se puede tener hijos. El Diccionario de la Lengua Española define la palabra núbil como: "Del lat. Nubilis. 1. adj. Dicho de una persona y más propiamente de una

\footnotetext{
${ }_{45}$ Tesis: VII.1o.P.145 P, publicada en el Semanario Judicial de la Federación y su Gaceta, Novena Época, Tomo 19, febrero de 2004, p. 1068, de rubro "Imputabilidad. Los artículos 34 de la ley de adaptación social y de los consejos tutelares para menores infractores y 66 de la Ley de Asistencia Social y Protección de Niños y Niñas del estado de Veracruz, que la establecen a partir de los dieciséis años de edad, no contravienen el artículo lo. de la convención sobre los derechos del niño, ni el principio de supremacía de los tratados internacionales."

${ }^{46}$ Convención sobre el Consentimiento para el Matrimonio, la Edad Mínima para Contraer Matrimonio y el Registro de los Matrimonios. Dof 19 de abril, 1983.
} 
mujer: Que está en edad de contraer matrimonio". ${ }^{47}$ En México, según lo establecen algunas legislaciones civiles del país, la edad núbil es de 14 años en la mujer y de 16 en el hombre; otras legislaciones establecen la edad de 16 años para ambos contrayentes.

En la edad núbil, las niñas y los niños se encuentran en condiciones peculiares de desarrollo, por lo cual el Comité de los Derechos del Niño describe la adolescencia como un periodo de desarrollo integral en el cual se suceden importantes transformaciones: cambios físicos, cognoscitivos y sociales; se adquiere la madurez sexual y reproductiva; adquisición gradual de la capacidad para asumir comportamientos y funciones de adultos, lo cual implica nuevas obligaciones y exige nuevos conocimientos teóricos y prácticos; así como la adquisición de una identidad personal y la gestión de su propia sexualidad. También es un periodo de cambios positivos, como la capacidad de aprender rápidamente, experimentar nuevas y diversas situaciones, desarrollar y utilizar el pensamiento crítico y familiarizarse con la libertad, ser creativos y socializar. ${ }^{48}$

Actualmente la edad núbil de catorce o dieciséis años indicada ya no es aceptada por otros organismos internacionales más progresistas en la protección de los derechos humanos de los niños. El Comité de los Derechos del Niño ha expresado su preocupación por que la legislación familiar de Estados parte como El Salvador y México permita que niñas de 14 años contraigan matrimonio en determinadas circunstancias, por ejemplo cuando han alcanzado la pubertad, cuando ya tienen un hijo o incluso si la niña está embarazada. El Comité y otros organismos internacionales alientan a los Estados a elevar y estandarizar la edad mínima para el matrimonio de niños y niñas, y para que adopten medidas para impedir los matrimonios precoces. ${ }^{49}$ El Comité recomienda legislar para elevar a dieciséis años la edad mínima para contraer matrimonio, sólo en casos excepcionales y con dispensa judicial. ${ }^{50}$

En este contexto, el Centro Virtual de Conocimiento para poner fin a la Violencia contra las Mujeres y Niñas señala que en la edad núbil el desarrollo mental y social de las personas se sigue produciendo, y de ningún modo significa que ya hayan adquirido la suficiente madurez para contraer matrimonio. Por tanto, es un criterio que responde a impresiones subjetivas sobre la madurez

\footnotetext{
${ }^{47}$ Real Academia Española, Diccionario de la Lengua Española. [Consulta: 23 de febrero, 2015]. Disponible en: http://www.rae.es/recursos/diccionarios/drae

${ }^{48}$ Comité de los Derechos del Niño. Observación General núm. 4, 2003, párrs. 2 y 9.

${ }^{49}$ Comité de los Derechos del Niño. Organización de las Naciones Unidas. El Salvador, CRC/C/SLV/ CO/3-4, párr. 25, 17 de febrero, 2010. Observaciones Finales; Comité de los Derechos del Niño Organización de las Naciones Unidas, México, GRC/C/MEX/CO/3, 8 de junio, 2006, párrs. 21 y 22. Observaciones finales; Comité de Derechos Económicos, Sociales y Culturales. Organización de las Naciones Unidas, México, E/C.12/CO/MEX/4, 9 de junio, 2006, párrs. 21 y 40. Observaciones finales. ${ }^{50}$ Comité de los Derechos del Niño. Organización de las Naciones Unidas, España, CRC/C/ESP/ CO/3-4, Inciso C.2, 3 de noviembre, 2010. Observaciones finales.
} 
sexual y el desarrollo físico de las personas. ${ }^{51}$ En este sentido, cuestionan las normas que permiten el matrimonio infantil, haciendo notar la necesidad de ofrecer una protección jurídica más amplia y efectiva que asegure de manera eficaz el adecuado desarrollo de los niños.

El Comité para la Eliminación de la Discriminación contra la Mujer ${ }^{52}$ expresa que no está de acuerdo en que los niños, por determinadas causas, alcancen antes la mayoría de edad, como sucede en México con la emancipación de los menores por razón de matrimonio. Este organismo internacional considera que la edad mínima para contraer matrimonio debe ser de 18 años tanto para el hombre como para la mujer, una vez que hayan alcanzado la madurez y la capacidad de obrar plenas.

Si bien la Convención sobre los Derechos del Niño no establece normativamente una edad mínima para contraer matrimonio, el Comité de los Derechos del Niño, en la Observación General número 4 de 2003, párrafo 20, señala que cuando los niños contraen matrimonio el desarrollo infantil se ve obstruido en un doble sentido: por un lado, interfiere en la satisfacción de sus necesidades primordiales; por otro, los priva de todas las medidas especiales de protección integral a que tienen derecho en virtud de la GDN, pues se les considera legalmente adultos aun cuando su edad sea menor a 18 años.

Por tal motivo, el Comité de los Derechos del Niño, a nivel de observación general, recomienda a los Estados parte que, cuando sea necesario, reformen sus leyes para aumentar la edad mínima para el matrimonio a los 18 años por igual para las chicas y los chicos, con o sin acuerdo de los padres, en consonancia con la evolución y madurez de sus facultades. ${ }^{53}$

La posición de los organismos internacionales más progresistas en erradicar el matrimonio infantil es muy firme. $\mathrm{Al}$ respecto, la Convención sobre la Eliminación de todas las Formas de Discriminación contra la Mujer establece en el artículo 16.2 que "No tendrán ningún efecto jurídico los esponsales y el matrimonio de niños y se adoptarán todas las medidas necesarias, incluso de carácter legislativo, para fijar una edad mínima para la celebración del matrimonio y hacer obligatoria la inscripción del matrimonio en un registro oficial".

El Consejo de Derechos Humanos de la ONU expone que en el año 2012 el Comité de los Derechos del Niño, el Comité para la Eliminación de la Discriminación contra la Mujer, la Representante Especial del Secretario General sobre la Violencia contra los Niños, el Grupo de Trabajo sobre la

\footnotetext{
${ }^{51}$ Centro virtual de conocimiento para poner fin a la violencia contra las mujeres y niñas. ONu Mujeres, Determinación de una edad mínima para el matrimonio. [Consulta: 10 de noviembre, 2015]. Disponible en: http://www.endvawnow.org/es/articles/616-determinacion-de-una-edad-minima-para-el-matrimonio.html

${ }^{52}$ Comité para la Eliminación de la Discriminación contra la Mujer. Recomendación General núm. 21,13 ${ }^{\circ}$ período de sesiones, 1994, párr. 36.

${ }^{53}$ Comité de los Derechos del Niño. Observación General núm. 4, 2003, párr. 20.
} 
Discriminación contra la Mujer en la Legislación y en la Práctica, así como cuatro titulares de mandatos de procedimientos especiales, emitieron una declaración conjunta en la que exhortaron a los Estados a elevar a 18 años la edad mínima para contraer matrimonio sin excepción. ${ }^{54}$

El Consejo de Derechos Humanos de la $\mathrm{ONU}^{55}$ elaboró un estudio en los Estados parte acerca de los problemas relacionados con el marco jurídico y la aplicación de las leyes sobre matrimonio infantil. Indica que en 147 países la legislación autoriza el matrimonio de menores de 18 años de edad, con el consentimiento de los tutores o con autorización judicial, o de otro tipo. De estos países, 54 aprueban que la edad de las niñas sea inferior a la de los niños. En otros países, la edad mínima para contraer matrimonio adopta como criterio ya sea la edad de responsabilidad penal, o la edad mínima para el consentimiento sexual, o el inicio de la pubertad o el embarazo.

En estos casos, las legislaciones sobre el matrimonio infantil son incompatibles con las obligaciones internacionales. El Consejo de Derechos Humanos de la ONU señala que cada vez es más frecuente que los Estados adopten medidas legislativas para prohibir el matrimonio infantil, y para elevar la edad mínima para contraer matrimonio a los 18 años, tanto para niñas como para niños. Asimismo, indica que diversos Estados, como la República Árabe, Siria, y Suecia, han establecido sanciones para quienes lleven a cabo prácticas como el matrimonio infantil, precoz y forzado. Señala los avances logrados en lo relativo por Albania, Azerbaiyán, Benín, Egipto, Francia, Guinea-Bissau, Kenya, Madagascar y la República de Corea.

El Consejo de Derechos Humanos de la onu expresa que aún persisten graves problemas en los Estados por la falta de adopción y aplicación de leyes para afrontar la existencia del matrimonio infantil, precoz y forzado. Recomienda la formulación y ejecución de políticas y estrategias nacionales con la amplia participación del Estado y de la sociedad civil, y otros interesados pertinentes, incluidos los legisladores y los jueces. ${ }^{56}$

Esta tendencia internacional plantea para el Estado mexicano la disyuntiva de mantener vigentes las disposiciones sobre el matrimonio infantil de acuerdo con los tratados internacionales que lo autorizan, y sin que ello sea causa de desprotección de los derechos humanos de los niños; o por el contrario, decidirse por armonizar la legislación civil con los tratados internacionales más progresistas que lo prohíben y recomiendan la edad mínima de 18 años para

\footnotetext{
${ }^{54}$ Organización de las Naciones Unidas. Asamblea General. Consejo de Derechos Humanos. A/ HRC/26/22, $26^{\circ}$ período de sesiones, 2 de abril, 2014, párr. 13.

${ }_{55}$ Organización de las Naciones Unidas. Asamblea General. Consejo de Derechos Humanos. A/ HRC/26/22, $26^{\circ}$ período de sesiones, párrs. 25 y 42, 2 de abril de 2014.

${ }^{56}$ Asamblea General. Consejo de Derechos Humanos. A/HRC/26/22, 26º período de sesiones, Prevención y eliminación del matrimonio infantil, precoz y forzado. Informe de la Oficina del Alto Comisionado de las Naciones Unidas para los Derechos Humanos, 2 de abril, 2014, párr. 53.
} 
contraer matrimonio, para que el Estado, la familia y la comunidad garanticen una protección más eficaz a los derechos humanos de los niños.

\section{AdECUACIÓN DE LA PROHIBICIÓN DEL MATRIMONIO INFANTIL EN LA LEGISLACIÓN CIVIL MEXICANA}

En un análisis prospectivo, en este artículo se plantea que la legislación civil del país, al permitir el matrimonio infantil, suprime o limita el goce y ejercicio de los derechos humanos de los niños. ${ }^{57} \mathrm{El}$ Estado mexicano tiene la obligación de legislar en el sentido que indican los tratados más progresistas en la protección de los derechos humanos de los niños, y el deber de eliminar todas las normas secundarias que los contravienen. Enseguida se analizan los principios constitucionales de interpretación que sustentan el deber del legislador de armonizar las normas civiles internas sobre el matrimonio, con las normas internacionales que prohíben el matrimonio infantil.

La obligación del legislador de expedir las leyes que prohíben el matrimonio infantil encuentra un primer sustento en el artículo 133 constitucional. Este artículo expresa el principio de supremacía constitucional, señalando que la Constitución y los tratados celebrados por México serán ley suprema de toda la Unión. Representa un sistema de fuentes del derecho, y en relación con el artículo 1 constitucional, diseña la incorporación de los tratados internacionales de derechos humanos, como fuente normativa del orden jurídico interno. Las fuentes de producción normativa y su aplicación se ordenan no a través de divisiones jerárquicas, sino como un bloque de constitucionalidad que actúa como punto de convergencia en la interpretación de los derechos humanos. ${ }^{58}$

En este sentido, los tratados internacionales como el Comité de los Derechos del Niño, el Comité para la Eliminación de la Discriminación contra la Mujer, así como el Consejo de Derechos Humanos de la ONU, para proteger de manera más eficaz los derechos humanos de los niños, han recomendado a los Estados parte legislar para prohibir el matrimonio infantil, y elevar a 18 años, tanto para la mujer como para el varón, la edad mínima para contraer matrimonio sin excepción.

La obligación de garantía del Estado y de sus autoridades ${ }^{59}$ de proteger los derechos humanos, se encuentra en el párrafo tercero del artículo $1^{\circ}$ constitucional, que señala que el Estado y sus autoridades en todos los niveles,

\footnotetext{
57 "Mona Lisa. El matrimonio infantil en México y sus implicaciones en las niñas y adolescentes", Biblioteca Virtual de la scjn, 2013, p. 4. [Consulta: 8 de diciembre, 2014]. Disponible en: http://www. equidad.scjn.gob.mx/biblioteca_virtual/concursos/2013-01-05.pdf

${ }^{58}$ Caballero Ochoa, José Luis, op. cit., p. 148.

${ }^{59}$ Balbuena, Pedro, Díaz Rodríguez, Luz, Tena de Sosa, Félix María (comps.), Los Principios Fundamentales del Proceso Penal Vistos por las Cortes de Apelación, Santo Domingo, República Dominicana, Fundación Institucionalidad y Justicia (Finjus)-Universidad Iberoamericana (Unibe), 2008, p. 12.
} 
tienen la obligación de proteger, respetar, y garantizar estos derechos. En un sentido restringido, se puede decir que las garantías son principalmente medios de carácter procesal que tienen como finalidad reparar las violaciones a los derechos humanos, y devolverlos a su estado original. ${ }^{60}$

En sentido amplio, las garantías comprenden todos los mecanismos, técnicas, medios y procedimientos establecidos en la Constitución y en los tratados en la materia, para la efectiva salvaguarda de los derechos humanos; pueden adoptar la forma de requisitos, restricciones, exigencias u obligaciones previstas para el Estado y sus autoridades. ${ }^{61}$ Ante su inexistencia, el goce de los derechos humanos no puede materializarse en las personas. ${ }^{62}$

El legislador, para garantizar la efectiva protección de los derechos humanos de los niños, tiene la obligación de interpretar ${ }^{63}$ las normas secundarias que afecten sus derechos humanos, de acuerdo con los principios que se exponen a continuación. El segundo párrafo del artículo 1 constitucional establece dos principios de interpretación de las normas sobre derechos humanos que tienen carácter de obligatoriedad para todas las autoridades del Estado: el principio de interpretación conforme, y el principio pro persona. Estos principios, en manos del legislador, son técnicas para la eficaz interpretación de los derechos humanos de los niños, ${ }^{64}$ frente a normas secundarias que los contravengan.

La interpretación conforme es un principio para la tutela de los derechos humanos de las personas, ${ }^{65}$ según el cual la interpretación de las leyes secundarias que hagan las autoridades será conforme con las normas de derechos humanos previstas en la Constitución y en los tratados internacionales en la

\footnotetext{
${ }^{60}$ Fix Zamudio, Héctor, "Breves reflexiones sobre el concepto y contenido del Derecho Procesal Constitucional”, en Ferrer MaC Gregor, Eduardo (coord.), Derecho Procesal Constitucional, México, Porrúa, 2003, p. 273.

${ }^{61}$ Tesis 1a. CGLXXXVI/2014 (10a.), publicada en Gaceta del Semanario Judicial de la Federación, Décima Época, libro 9, tomo I, agosto de 2014, p. 529, de rubro "Derechos humanos. Naturaleza del concepto 'garantías de protección', incorporado al artículo 1 de la Constitución Federal, vigente desde el 11 de junio de 2011"; Tesis 1a. CCLXXXVII/2014 (10a.), publicada en la Gaceta del Semanario Judicial de la Federación, Décima Época, libro 9, tomo I, agosto de 2014, p. 528, de rubro "Derechos humanos. Conforme al artículo 1 de la Constitución Federal, vigente desde el 11 de junio de 2011, las garantías para su protección pueden adoptar un carácter positivo o negativo".

${ }^{62}$ Tesis VI. ${ }^{\circ}$. A.30 A, publicada en el Semanario Judicial de la Federación y su Gaceta, Décima Época, libro 11, tomo 2, agosto de 2012, p. 1702, de rubro "Contencioso administrativo del estado de puebla. La ausencia de un tribunal de dicha naturaleza en esa entidad federativa, no resulta violatoria de las garantías judiciales y de la protección judicial previstas, respectivamente, en los artículos 8, numeral 1, y 25 de la convención americana sobre derechos humanos".

${ }^{63}$ Luna Escudero, Víctor, "La nueva cultura jurídica en México. El Juez Nacional y los retos del control de Convencionalidad", en García Villegas Sánchez Cordero, Paula M., El control de convencionalidad y las cortes nacionales, pp. 85-101, México, Porrúa, 2013, p. 94.

${ }^{64}$ Carbonell, Miguel, El ABC de los derechos humanosy del control de convencionalidad, México, Porrúa, 2015, p. 93.

${ }^{65}$ Tesis: XX.3o.2 P (10a.), publicada en el Semanario Judicial de la Federación y su Gaceta, Décima Época, libro 25, tomo 3, octubre de 2013, p. 1736, de rubro "Amparo indirecto contra el auto de formal prisión. Bajo el método de interpretación conforme y los principios pro personae y de progresividad, la demanda puede presentarse hasta antes del dictado de la sentencia definitiva (legislación vigente a partir del 3 de abril de 2013)".
} 
materia. ${ }^{66}$ La interpretación conforme es una cláusula de tutela y garantía, ${ }^{67}$ por medio de la cual es posible que las normas de derechos humanos de los niños establecidos en la Constitución se amplíen al armonizar su contenido con los tratados internacionales en la materia. ${ }^{68}$ De esta forma, resulta posible integrar al orden jurídico interno las normas internacionales de derechos humanos de los niños que, para su garantía, prohíben el matrimonio infantil.

Lo anterior de ningún modo significa que el legislador primero analice la Constitución para llevar a cabo la interpretación de los derechos humanos de los niños, y después acuda a los tratados. De acuerdo con el bloque de constitucionalidad, la interpretación conforme favorecerá siempre el derecho humano que mejor proteja a los niños, sin interesar si su reconocimiento y validez se exponen desde la Constitución o desde los tratados, toda vez que se armonizan ambas fuentes normativas.

La interpretación que mejor favorezca el derecho humano es la expresión del principio pro persona. De acuerdo con este último principio, si sobre una norma jurídica secundaria son posibles diferentes interpretaciones, todas las autoridades del país tienen la obligación de adoptar la interpretación que mayor protección ofrezca al derecho humano, sean las de fuente normativa de la Constitución Federal o las de fuente normativa internacional.

De acuerdo con el principio de la norma más favorable al ser humano, ${ }^{69}$ el legislador, al prohibir en la legislación civil el matrimonio infantil, cumple con su obligación de optar por los estándares internacionales que ofrecen mayor protección a los derechos humanos de los niños, lo cual redunda en la ampliación progresiva de estas normas en la Constitución. Al optar por este tipo de tratados, el legislador cumple con el principio del interés superior del menor, el cual tiene dos funciones normativas: a) como principio jurídico garantista y, b) como pauta interpretativa para solucionar los conflictos entre los derechos de los menores. ${ }^{70}$

Como principio jurídico garantista, el interés superior del menor es una de las garantías más importantes para resguardar la autonomía, la igualdad

\footnotetext{
${ }^{66}$ Castellanos Madrazo, José F., El control de constitucionalidad de la ley en México, op. cit., p. 445.

${ }^{67}$ Ruíz Matías, Alberto y Ruíz Jiménez L. M. "El principio pro homine en el sistema jurídico mexicano", en García Villegas Sánchez Cordero, Paula M., El control de convencionalidady las cortes nacionales, pp. 121144, México, Porrúa, 2013, p. 124.

${ }^{68}$ Ferrer Mac-Gregor, Eduardo. "Interpretación conforme y control difuso de convencionalidad. El nuevo paradigma para el juez mexicano", Estudios Constitucionales, año 9, núm. 2, pp. 531-622, Centro de Estudios Constitucionales de Chile Universidad de Talca, 2011, p. 549.

${ }^{69}$ Tesis: 1a. CGCXXVII/2014 (10a.), publicada en el Semanario Judicial de la Federación y su Gaceta, Décima Época, libro 11, tomo 1, octubre de 2014, de rubro "Principio pro persona. Requisitos mínimos para que se atienda el fondo de la solicitud de su aplicación, o la impugnación de su omisión por la autoridad responsable".

${ }^{70}$ Tesis 1a. CXXI/2012 (10a.), publicada en el Semanario Judicial de la Federación y su Gaceta, Décima Época, libro 9, tomo 1, junio de 2012, p. 261, de rubro "Interés superior del menor. Sus alcances y funciones normativas".
} 
y dignidad de los niños. Asociado con este principio se encuentra el principio de autonomía progresiva, el cual reconoce que la capacidad del niño para decidir sobre los asuntos que le conciernen evoluciona gradualmente conforme va alcanzando cierto grado de madurez. La Declaración de los Derechos del Niño, en su artículo 5, señala que el niño, en consonancia con la evolución de sus facultades, puede ejercer progresivamente sus derechos. En tanto el niño no tenga esa capacidad, para el pleno desarrollo de su personalidad y la satisfacción de sus necesidades, el Estado debe proveer lo necesario para propiciar el respeto a la dignidad de la niñez y el ejercicio pleno de sus derechos dentro del núcleo familiar, como espacio preferente de su desarrollo, pero también fuera de él. ${ }^{71}$

La CDN dice, en su artículo 3, párrafo primero, que en todas las medidas concernientes a los niños que tomen, entre otros, los órganos legislativos y judiciales, se atenderá ante todo el interés superior del niño, buscando su beneficio directo para garantizar y proteger su desarrollo y el ejercicio pleno de sus derechos, ${ }^{72}$ por lo cual sería inadmisible cualquier norma que los contraviniera. ${ }^{73}$ En el mismo sentido, la Corte Interamericana de Derechos Humanos ha dicho que el desarrollo del niño y el ejercicio pleno de sus derechos deben ser considerados como criterios rectores para la elaboración y aplicación de normas en todos los órdenes relativos a la vida del niño. ${ }^{74}$

Para que estos derechos no se vean interrumpidos con el matrimonio, el Comité de los Derechos del Niño hizo la siguiente observación general a los Estados parte: legislar para que las disposiciones jurídicas específicas estén garantizadas en derecho interno, entre ellas las relativas al establecimiento de la edad mínima para el consentimiento sexual y el matrimonio. ${ }^{75}$

El párrafo tercero del artículo 1 constitucional señala que todas las autoridades tienen la obligación de promover, respetar, proteger y garantizar los derechos humanos de conformidad con los principios de universalidad, interdependencia, indivisibilidad y progresividad. En la interpretación que lleve a cabo el legislador al crear las normas secundarias relacionadas con

\footnotetext{
${ }^{71}$ Tesis I.3 $3^{\circ}$. C.918 C, publicada en el Semanario Judicial de la Federación y su Gaceta, Novena Epoca, tomo 33, febrero de 2011, p. 2327, de rubro: "Familia. Constituye la forma óptima de desarrollo del menor (interpretación de los artículos 138 ter, 138 quáter, 138 quintus y 138 sextus del código civil para el distrito federal)".

${ }^{72}$ Tesis 1a. CCLXV/2014 (10a.), publicada en el Semanario Judicial de la Federación y su Gaceta, Décima Época, libro 8, tomo 27, 11 de julio de 2014, p. 155, de rubro "Nulidad de matrimonio. El interés superior del menor no justifica el estudio oficioso de la causa que la declaró”; Tesis P.XXV/2008, publicada en el Semanario Judicial de la Federación y su Gaceta, Novena Epoca, tomo 27, junio de 2008, p. 659, de rubro "Menores de dieciocho años. El análisis de una regulación respecto de ellos debe hacerse atendiendo al interés superior y a la prioridad de la infancia".

${ }^{73}$ González Contró, Mónica, Derechos Humanos de los niños: una propuesta de fundamentación, México, Universidad Nacional Autónoma de México, 2008, p. 407.

${ }^{74}$ Tesis 1a./J. 25/2012 (9a.), publicada en el Semanario Judicial de la Federación y su Gaceta, Décima Época, libro 15, tomo 1, diciembre de 2012, p. 334, de rubro "Interés superior del menor. Su concepto". ${ }^{75}$ Comité de los Derechos del Niño. Observación General núm. 4 (2003), párr. 9.
} 
los derechos humanos de los niños, es de suma importancia el principio de progresividad, pues debe legislar siempre en la dirección de lograr su mayor efectividad, es decir, seguir avanzando en la garantía, protección y desarrollo de sus derechos humanos. ${ }^{76}$

El principio de interpretación progresiva implica que los derechos humanos no son instrumentos estáticos, sino instrumentos vivos que deben interpretarse de acuerdo con la evolución histórica y las condiciones de vida actuales. ${ }^{77}$ En el mismo sentido, la Suprema Corte de Justicia de la Nación ha sostenido que el contenido de los derechos humanos no se limita al texto expreso de la norma donde se reconoce dicho derecho, sino que se va robusteciendo con la interpretación evolutiva o progresiva que hagan tanto los tribunales constitucionales nacionales como los organismos internacionales, en una relación dialéctica. ${ }^{78}$

Es importante subrayar que, una vez alcanzado un determinado nivel de progresividad en los derechos humanos de los niños, no se debe retroceder ni reducir su contenido formal y material. ${ }^{79}$ Para seguir avanzando en la protección de los derechos humanos de los niños (por ejemplo, para evitar la discriminación de la mujer en el matrimonio al establecer una edad menor que la del hombre), el legislador debe igualar en ambos la edad mínima para contraer matrimonio. Sin embargo, tiene la obligación de cumplir con el principio de no regresividad, es decir, no crear normas regresivas-limitantes de las garantías de protección de los derechos humanos; por lo tanto, al armonizar la normatividad civil interna con los tratados internacionales más progresistas, debe establecer en 18 años la edad mínima para contraer matrimonio, por igual para hombres y mujeres.

En suma, para el legislador los principios constitucionales de interpretación de los derechos humanos son principios que justifican que al integrar en el orden jurídico interno los tratados internacionales que prohíben el matrimonio infantil, se maximicen los derechos humanos de los niños, dotándolos de mayor eficacia. De lo anterior resulta la obligación del Estado ${ }^{80}$ de llevar a cabo las medidas legislativas necesarias para la efectiva protección de los derechos humanos de los niños. Asimismo, debe garantizar un marco jurídico homogéneo en todo el país, pues los tratados internacionales son obligatorios para los Estados parte en la totalidad de su territorio.

\footnotetext{
${ }^{76}$ Vázquez, Luis Daniel y Serrano, Sandra, "Los principios de universalidad, interdependencia, indivisibilidad y progresividad. Apuntes para su aplicación”, en Carbonell, Miguel y Salazar, Pedro (coords.), La reforma constitucional de derechos humanos, pp. 135-165, México, Porrúa, 2014, p. 159.

${ }^{77}$ Corte Interamericana de Derechos Humanos. Caso de la "Masacre de Mapiripán" vs. Colombia, párr. 106, septiembre de 2005.

${ }^{78}$ Tesis 1a. CDV/2014 (10a.), publicada en el Semanario Judicial de la Federación y su Gaceta, Décima Época, libro 12, tomo 1, noviembre de 2014, p. 714, de rubro "Derechos humanos. Su contenido no se limita al texto expreso de la norma que lo prevé, sino que se extiende a la interpretación que los órganos autorizados hagan al respecto".

${ }^{79}$ Castilla Juárez, Karlos, op. cit., p. 157.

${ }^{80}$ Carbonell, Miguel, "Las obligaciones del Estado en el artículo $1^{\circ}$ de la Constitución Mexicana”, op. cit., p. 76
} 
Si el Estado incumple con su obligación de legislar y prohibir el matrimonio infantil, la parte agraviada en sentido estricto no son los Estados contrapartes adheridos a dichos tratados, sino los niños, por la afectación de sus derechos humanos. De acuerdo con el criterio de la Corte Interamericana de Derechos Humanos, cuando un Estado no legisla en el sentido en el que recomienda un tratado que le resulta vinculatorio, puede incurrir en responsabilidad internacional. En el presente caso, el Estado mexicano puede asumir responsabilidad internacional en un doble sentido. Limita o suprime los derechos humanos de los niños, en primer lugar, al continuar con la práctica del matrimonio infantil a la edad mínima de 14 años en la mujer y de 16 años en el varón; en segundo lugar, al omitir dictar las normas a que está obligado para establecer la edad mínima de 18 años para contraer matrimonio. ${ }^{81}$

\section{CONCLUSIONES}

El nuevo paradigma de derechos humanos adoptado por la Constitución Federal es un mecanismo que impulsa en México el progreso de estos derechos al mismos ritmo en que evolucionan los tratados internacionales que en la materia le resultan vinculatorios. La expedición de la Ley General sobre Derechos Humanos de las Niñas, los Niños y los Adolescentes, en diciembre de 2014, representa una nueva etapa en la evolución de estos derechos en México. El legislador se dio a la tarea de adecuar su contenido con los tratados internacionales en la materia, principalmente con la Convención sobre Derechos del Niño, en observancia a lo dispuesto por el artículo 4 constitucional.

Los instrumentos internacionales señalan que, de acuerdo con las características que ha adquirido la sociedad moderna, las niñas, niños y adolescentes requieren de especiales factores sociales, económicos, educativos, culturales y familiares imprescindibles para un desarrollo integral. Debido a la importancia de estos factores, los Estados parte están obligados a garantizarlos como derechos humanos en su legislación interna, así como a eliminar todas aquellas normas secundarias que los limitan o suprimen, como sucede con el matrimonio infantil.

La legislación civil del país establece el derecho de los menores de edad para contraer matrimonio, siempre que sea con el consentimiento de sus tutores o en su caso del juez civil. Esta normatividad no contradice los tratados internacionales que reconocen a los menores de edad el derecho de contraer matrimonio. El problema es que en el contexto de la sociedad moderna, los tratados internacionales más progresistas en la materia no

\footnotetext{
${ }^{81}$ Corte Interamericana de Derechos Humanos. Opinión Consultiva OG-14/94 "Responsabilidad internacional por expedición y aplicación de leyes violatorias de la Convención (artículos 1 y 2 de la Convención Americana sobre Derechos Humanos), 9 de diciembre de 1994, párrs. 32, 37 y 38.
} 
están de acuerdo con que se otorgue ese derecho a los niños. Señalan que la emancipación de los menores de edad en razón del matrimonio trae consigo la pérdida de los derechos del niño, lo cual agudiza su estado de vulnerabilidad. El Comité de los Derechos del Niño, el Comité para la Eliminación de la Discriminación contra la Mujer, así como el Consejo de Derechos Humanos de la onu, para proteger los derechos humanos de los niños prohíben en su normatividad el matrimonio infantil, y hacen recomendaciones y observaciones generales a los Estados parte sobre establecer la edad mínima de 18 años para contraer matrimonio.

El nuevo paradigma de derechos humanos en México (fundamentalmente el principio de supremacía constitucional, los principios constitucionales de progresividad, interpretación conforme y pro persona), en relación con el principio del interés superior del menor, justifica plenamente la obligación del Estado mexicano de legislar para armonizar la legislación civil con los tratados internacionales más progresistas en la protección de los derechos humanos de los niños. Mientras el Estado mexicano no cumpla con esta obligación, la legislación civil contraviene los derechos humanos de los niños, e incurre en responsabilidad internacional.

Los beneficios sociales que traería consigo elevar a 18 años la edad mínima para contraer matrimonio son muy variados: no interrumpir el desarrollo de los adolescentes, fortalecer la prevención y erradicación del matrimonio infantil, contribuir a resolver el problema del embarazo y la maternidad adolescentes, combatir la desigualdad entre la mujer y el hombre en la edad para contraer matrimonio, avanzar en la erradicación de las prácticas y costumbres tradicionales sobre el matrimonio forzado, el abandono de la escuela al adquirir obligaciones de una persona mayor, el desempleo de adolescentes por falta de preparación, entre otros. 